\title{
An investigation on parenting stress of children with cystic fibrosis
}

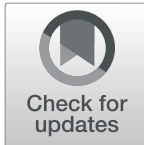

\author{
Grazia Isabella Continisio ${ }^{1 \dagger}$, Nicola Serra ${ }^{2 *}$, Assunta Guillari ${ }^{3}$, Maria Teresa Civitella', Angela Sepe ${ }^{1}$, Silvio Simeone ${ }^{4}$, \\ Gianpaolo Gargiulo ${ }^{3}$, Silvia Toscano ${ }^{1}$, Maria Rosaria Esposito ${ }^{5}$, Valeria Raia ${ }^{1}$ and Teresa Rea ${ }^{3}$
}

\begin{abstract}
Background: The management of chronic diseases, particularly in children, requires an integrated physical and psychological approach to both sick children and their family. This is the case of Cystic Fibrosis (CF), a complex genetic chronic disease, where, a comprehensive evaluation of the emotional impact and an effective multidimensional approach are indicated.
\end{abstract}

Aim: This study investigates on parenting stress in children and adolescents with CF and its determinants related to parents, children and the disease severity.

Methods: The study involved 34.04\% adult males and 65.96\% adult females (range 21-55 years) and 47 children with CF, 54.35\% males and $45.65 \%$ females (range 1-17 years). The data were obtained through a Parenting Stress Index - Short Form (PSI-SF) questionnaire. According to the PSI-SF scoring system, three types of stress were detected: a typical stress pattern (normal), a high stress pattern (increased) and a defensive response, which may be considered as a high stress feature in children which requires monitoring and clinical evaluation.

Results: This study shows a significant presence of stress in females (60.23\%), of subject married (84.62\%), unemployed (69.23\%) and with education level such as "middle School" (61.54\%). Concerning children of parents with high stress, it resulted most frequent children with one sibling (53.85\%). Finally, by univariate analysis, it resulted a significant positive correlation between parenting stress and disease degree of children. Instead by multivariate analysis, we found that the variables: Number of siblings and Birth order were a significant positive and negative predictor of parenting stress respectively.

Conclusion: An increased stress level was detected in less than one third of parents of subjects with CF. These data may be related to the psychological support which is part of the routine management of CF care team. However, as children's features seem to act as a determinant of stress more than parental ones, the parental-child dysfunction should be the target for further integrated interventions.

Keywords: Parenting stress index, Cystic fibrosis, Child, Clinical management, Biopsychosocial model

\footnotetext{
*Correspondence: nicola.serra@unina.it

${ }^{\dagger}$ Grazia Isabella Continisio and Nicola Serra contributed equally to this work.

${ }^{2}$ Department of Molecular Medicine and Medical Biotechnology, University Federico II of Naples, Naples, Italy

Full list of author information is available at the end of the article
}

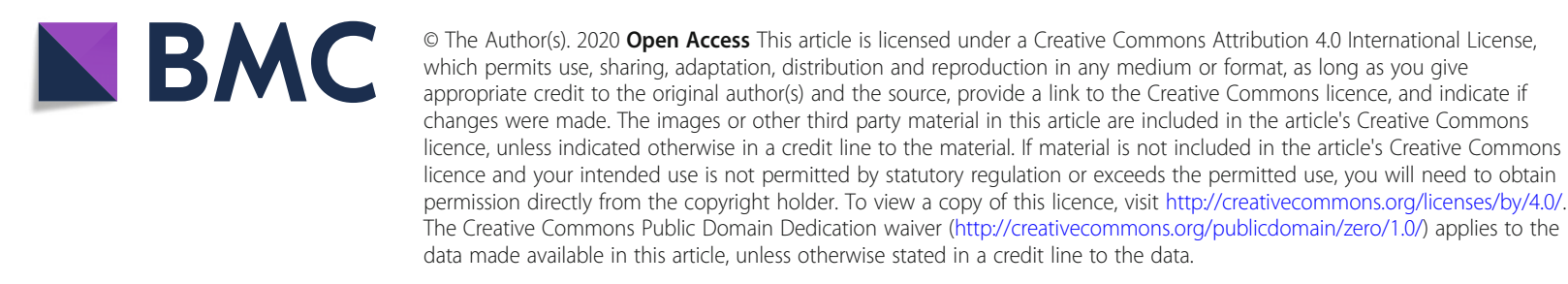




\section{Background}

Cystic Fibrosis (CF) is the most common serious genetic disease in Caucasian populations, resulting in clinical symptoms in multiple body systems as lung, sinus, gastrointestinal and reproductive tracts. Standard of care includes monitoring pulmonary function, nutritional status, airway clearance, and infection control [1]. Newer oral agents that are based on specific mutations are providing physicians with the ability to target underlying CFTR gene defects, thus leading to an increased life expectancy over 50 years [2] in patients with CF.

However, there is no evidence that chronic time consuming conventional therapies can be stopped and CF still represents a paradigmatic clinical scenario requiring a multidimensional approach for patients and their families among chronic diseases [3].

With regard to families, it has seemed interesting to investigate the degree of stress in parents of children affected by this disease, as caregivers' psychological wellness is hardly ever taken into consideration during the treatment paths of pediatric patients. In addition, since parenting stress is a common part of parenting experience and it usually occurs when either parents' commitment exceeds their own internal resources, we have considered understanding how a parent of a child with CF may feel in the light of both their practical and emotional commitment involved.

There is evidence that shows that caregivers of children with a chronic illness report significantly higher general parenting stress than caregivers of healthy children [4-7]. Furthermore, parenting stress is crucial to understand any family dysfunction and/or psychopathology [8]. However, it still remains unclear whether or not and to what extent parental distress is a major feature of cystic fibrosis $[9,10]$.

The aim of the study is to understand whether this disease may induce a stress pattern in parents of children and adolescents with CF, analyze parental stress severity as well as identify any further correlations with additional factors.

\section{Methods}

\section{Sampling and eligibility}

This study was performed at the Cystic Fibrosis Unit of the University-Hospital Federico II in Naples. The sample included 47 adult parents $(34.04 \%$ males and $65.96 \%$ females) mean age 38.87 , and 47 children (54.35\% males and $46.65 \%$ females) mean age 8.26 .

Informed consent was obtained from all parents of children included in the study. For all participants anonymity was guaranteed. No economic incentives were offered or guaranteed for their participation in the study.

The inclusion criteria required to be a parent of a child affected by cystic fibrosis as well as their informed consent. The Local Ethical Committee approved the study. (Protocol number 2018: 254/2018).

\section{Instrument}

The data were obtained through the Parenting Stress Index - Short Form (PSI-SF) questionnaire which was designed by Richard R. Abidin [11, 12]. The PSI-SF is a standardized questionnaire which can be filled in by parents without any specific help and is widely used in the clinical practice. It aims to assess parents distress in relation to their child and the context in which the relationship takes place. The stress evaluated by the questionnaire was defined as the discrepancy perceived by parents between the needs imposed by the circumstances related to parenting and the resources available to address them. The PSI-SF included 36 items which were assessed according to the Likert scale. The answers revealed the extent of agreement or disagreement to the proposed statement. There are five categories of agreement: strongly agree $(S A)$, agree $(A)$, not sure (NS), disagree (D) and strongly disagree (SD). Furthermore, the questionnaire was divided into three parts:

1. Parenting Distress - PD. This part analyses the stress dependent on the parent only and not necessarily on the child. It defines the level of stress that the parent perceives on the basis of his/her parenting ability as well as if there is a possible conflict with the other parent or another family component (Questions 1 to 12).

2. Parent-Child Dysfunctional Interaction - P-CDI. This section examines the parent-child relationship which depends both on the parent and the child. The parent perceives that the relationship with his/ her child is different from his/her own expectations and from other parents with their children (Questions 13 to 24).

3. Difficult Child (DC). This area focuses on the parents perception of their child by describing their perception of the difference between their own and other children in relation to their expectations (Questions 25 to 36).

In addition, two further parameters were obtained:

- the Defensive Response (DEF), which studies the respondent's defensive attitude, i.e. it evaluates the parent's honesty about the answers.

- Total stress which assesses whether or not the parents stress is globally increased using a global score.

\section{Procedure to evaluate stress}

According to the 5-point Likert scale, each category was associated with a number from 1 to 5 where 5 accounts 
for "strong agreement" and 1 for "strong disagreement". In the first step, the defensive responses of items 1, 2, 3, 7, 8, 9 and 11 were added and the resulting figure was recorded in the "Defensive response" box. Subsequently, the scores of the subscales were calculated: items from 1 to 12 were added and the total was entered in the "PD" variable. Then, items from 13 to 24 were added and the total sum was recorded in the "P-CDI" variable. Finally, the total sum of items 25 to 36 was assigned to the "DC" variable. The total stress score was obtained by adding the scores of PD, P-CDI and DC and the result was entered in the "Total Stress" variable.

Depending on child age range, a score or range was identified for each subscale and the relevant percentile corresponding to each score of the PSI-SF Italian version [12] was calculated.

For a better understanding of the severity stress, the results were classified into three categories:

1. from $1^{\text {st }}$ to $10^{\text {th }}$ percentile, the stress pattern was referred to as suspicious stress;

2. from $15^{\text {th }}$ to $80^{\text {th }}$ percentile the stress was normal and referred to as normal stress;

3. from $85^{\text {th }}$ to $100^{\text {th }}$ percentile the stress was considered as high or clinically significant and it was referred to as high stress

\section{Statistical analysis}

The statistical analysis was performed using the Matrix Laboratory (MATLAB) analytical toolbox version 2008 (MathWorks, Natick, MA, USA). The data were expressed in terms of figures and percentages for the categorical variables while the continuous data were determined as the mean \pm standard deviation unless otherwise specified. The $X^{2}$ test and was performed to assess any significant differences in proportions or percentages between the two independent groups. $X^{2}$ test with Yates continuity correction was used where the $x^{2}$ test was not appropriate. In addition, the Binomial test was performed to compare two mutually exclusive proportions. Any significant difference between the two means was evaluated by the Student's ttest. Multiple comparison chi-square tests were carried out to highlight any significant differences among the percentages. In that case, if the chi-square test was significant ( $p$-value $<0.05)$, a residual analysis with post hoc Z-test was performed.

Finally, a univariate and multivariate linear regression analysis was performed. The statistical test on Pearson's linear correlation coefficient $(\mathrm{R})$ was performed with the Student $\mathrm{t}$ test, under a null hypothesis of Pearson's linear correlation coefficient $R=0$. For the analysis, the dependence variable assumed was Total stress which was obtained according to the Parenting stress index (PSI-
SF) and Age of parents, Gender of parents, Civil status, Job, Education level, Age of children, Gender of children, Age at diagnosis, Number of siblings of $\mathrm{CF}$ child, birth order of CF child. Variables were numerically labelled as follows:

- Gender: male $=1$ and female $=0$

- Civil status: married $=1$ and not married $=0$

- Job: worker with income $=1$ and unemployed $=0$

- Education: low school =1, middle school = 2, high school $=3$, higher education degree $=4$.

- Clinical Severity: low $=1$, moderate $=2$, severe $=3$

All tests with $p$-value $(p)<0.05$ were considered significant.

\section{Results}

Table 1 shows the characteristics of both parents and children.

Statistical tests were performed for each variable. As expected, there were more mothers than fathers as key responders $(p<0.0001)$ as well as married versus unmarried parents $(89.36 \%>10.64 \%, p<0.0001)$. More frequently, parents had a "Middle School" education level $(53.19 \%, p=0.0005)$ and $51.32 \% \%$ reported a regular job.

As to CF children's features, their mean age was about 8 years and $54.35 \%$ of these were males. In addition, children with no $(40.43 \%, p=0.0344)$ or one $(42.55 \%, p=$ 0.0161 ) sibling were more frequent whilst the most frequent birth order was "first" child $(59.57 \%, p<0.0001)$. Finally, in terms of disease severity, the most frequent degree was "low" whereas "severe" was significantly less frequent compared to other severity degrees.

Table 2 reports two groups: Mother and Father.

The Mother's group was composed of 31 female individuals aged between 21 and 53 years (mean $37.71 \pm$ 8.17, of 8.17 years), while the Father's group included 16 individuals aged between 28 and 55 years, (mean of 41.13 years \pm 7 ). There were no statistical differences between the two groups. Similarly, there was no significant difference $(p=0.209)$ among the sub-categories with normal stress: PD $(74.47 \%=35 / 47)$, P-CDI $(55.32 \%=26$ / $47)$, DC $(70.21 \%=33 / 47)$ and DEF $(70.21 \%=33 / 47)$. Overall the majority of the population reported normal stress. However 1 out of 4 parents reported high stress with no major difference between mothers and fathers. The evaluation on variables revealed no significant differences between mothers and fathers in terms of high stress. These results are similar in each of the following sub-categories: PD $(12.5 \%=2 / 16<32.26 \%=10 / 31, p=$ $0.263)$, P-CDI $(50 \%=8 / 16>41.94 \%=13 / 31, p=0.828)$, DC $(31.25 \%=5 / 16>29.03 \%=9 / 31, p=0.858)$ and DEF $(25 \%=4 / 16<32.26 \%=10 / 31, p=0.858)$. 
Table 1 Characteristics of 47 parents and children participating in the study

\begin{tabular}{|c|c|c|}
\hline Parent's characteristics & Percentage/ mean \pm StD & Statistical analysis \\
\hline Age & 38.87 y.o. \pm 8.01 y.o. & \\
\hline \multicolumn{3}{|l|}{ Gender } \\
\hline Male & $34.04 \%(16 / 47)$ & $34.04 \%<65.96 \%, p<0.0001^{\mathrm{a}}(\mathrm{B})$ \\
\hline Female & $65.96 \%(31 / 47)$ & \\
\hline \multicolumn{3}{|l|}{ Civil status } \\
\hline Not married & $10.64 \%(5 / 47)$ & $10.64 \%<89.36, p<0.0001^{a}(B)$ \\
\hline Married & $89.36 \%(42 / 47)$ & \\
\hline \multicolumn{3}{|l|}{ Job } \\
\hline Worker with income & $48.68 \%(21 / 47)$ & $48.68 \%<51.32 \%, p=0.72(\mathrm{~B})$ \\
\hline Unemployed & $51.32 \%(26 / 47)$ & \\
\hline Education level & & $p<0.0001 *(C)$ \\
\hline Elementary school & $2.13 \%(1 / 47)$ & Elementary school ${ }^{c}, p=0.0024(Z)$ \\
\hline Middle school & $53.19 \%(25 / 47)$ & Middle school ${ }^{\mathrm{b}}, p=0.0005(\mathrm{Z})$ \\
\hline High school & $27.66 \%(13 / 47)$ & \\
\hline Higher Education & $17.02 \%(8 / 47)$ & \\
\hline Children's characteristics & Percentage/ mean \pm StD & Statistical analysis \\
\hline Age & 8.26 у.о. \pm 4.83 у.о. & \\
\hline \multicolumn{3}{|l|}{ Gender } \\
\hline Male & $54.35 \%(25 / 47)$ & $54.35 \%>45.65 \%, p=0.23(\mathrm{~B})$ \\
\hline Female & $45.65 \%(22 / 47)$ & \\
\hline Age at diagnosis & 1.64 y.o \pm 1.39 y.o. & \\
\hline Number of siblings & & $p<0.0001^{\mathrm{a}}(\mathrm{C})$ \\
\hline None & $40.43 \%(19 / 47)$ & Zero $^{b}, p=0.0344(Z)$ \\
\hline One & $42.55 \%(20 / 47)$ & One $^{b}, p=0.0161(Z)$ \\
\hline Two & $12.77 \%(6 / 47)$ & \\
\hline Three & $4.26 \%(2 / 47)$ & Three ${ }^{c}, p=0.0044(Z)$ \\
\hline Birth order & & $p<0.0001^{\mathrm{a}}(\mathrm{C})$ \\
\hline First & $59.57 \%(28 / 47)$ & First $^{b}, p<0.0001$ (Z) \\
\hline Second & $36.17 \%(17 / 47)$ & \\
\hline Third & $2.13 \%(1 / 47)$ & Third $^{c}, p=0.0017(Z)$ \\
\hline Fourth & $2.13 \%(1 / 47)$ & Fourth ${ }^{c}, p=0.0017(Z)$ \\
\hline Clinical Severity & & $p<0.0001^{\mathrm{a}}(\mathrm{C})$ \\
\hline Low & $53.19 \%(25 / 47)$ & Low $^{b}, p<0.0141$ (Z) \\
\hline Moderate & $34.04 \%(16 / 47)$ & \\
\hline Severe & $10.64 \%(5 / 47)$ & Severe $^{c}, p<0.0087(Z)$ \\
\hline Not defined & $2.13 \%(1 / 47)$ & \\
\hline
\end{tabular}

+ stress expressed in percentiles and evaluated according the PSI-SF scale, ${ }^{a}=$ significant test, ${ }^{b}=$ most frequent, ${ }^{c}=$ less frequent, $B=$ exact Binomial test, $C=$ Multiple comparison $\mathrm{x}^{2}$ test, $\mathrm{Z}=\mathrm{Z}$-test, $\mathrm{CY}=\mathrm{x}^{2}$ test with Yates correction, $\mathrm{StD}=$ standard deviation

In addition for high stress, there were not any remarkable differences among PD (21.28\%), P-CDI (25.53\%) and DC (23.41\%) subscales. A similar result was reported for normal stress (74.47, 55.32 and $70.21 \%$, respectively), while for suspicious stress (4.26, 19.15 and 6.38\% respectively) there was a significant difference ( $p=$ 0.0033). Finally, also the cases with high stress including suspicious stress $(25.53,44.68$ and $29.79 \%$ respectively) bore no significant differences $(p=0.12)$. In short, PD, P-PCI and DC subscales had similar association pattern. 
Table 2 Stress evaluation on the total sample, male and female group

\begin{tabular}{|c|c|c|c|c|}
\hline Stress evaluation & Male and Female & Male & Female & Male vs Female \\
\hline PD: Suspicious Stress & $4.26 \%(2 / 47)$ & $0.00 \%(0 / 16)$ & $6.45 \%(2 / 31)$ & $0.00 \%<6.45 \%, p=0.78(C Y)$ \\
\hline PD: Normal Stress & $74.47 \%(35 / 47)$ & $87.50 \%(14 / 16)$ & $67.74 \%(21 / 31)$ & $87.50 \%>67.74 \%, p=0.26(C Y)$ \\
\hline PD: High stress & $21.28 \%(10 / 47)$ & $12.5 \%(2 / 16)$ & $25.81 \%(8 / 31)$ & $12.5 \%<25.81 \%, p=0.50(\mathrm{CY})$ \\
\hline P-CDI: Suspicious Stress & $19.15 \%(9 / 47)$ & $31.25 \%(5 / 16)$ & $12.90 \%(4 / 31)$ & $31.25 \%>12.90 \%, p=0.26(C Y)$ \\
\hline P-CDI: Normal Stress & $55.32 \%(26 / 47)$ & $50.00 \%(8 / 16)$ & $58.06 \%(18 / 31)$ & $50.00 \%<58.06 \%, p=0.83(\mathrm{CY})$ \\
\hline P-CDI: High stress & $25.53 \%(12 / 47)$ & $18.75 \%(3 / 16)$ & $29.03 \%(9 / 31)$ & $18.75 \%<29.03 \%, p=0.68(C Y)$ \\
\hline DC: Suspicious Stress & $6.38 \%(3 / 47)$ & $6.25 \%(1 / 16)$ & $6.45 \%(2 / 31)$ & $6.25 \%<6.45 \%, p=0.55(\mathrm{CY})$ \\
\hline DC: Normal Stress & $70.21 \%(33 / 47)$ & $68.75 \%(11 / 16)$ & $70.97 \%(22 / 31)$ & $68.75 \%<70.97 \%, p=0.86(C Y)$ \\
\hline DC: High stress & $23.41 \%(11 / 47)$ & $25.00 \%(4 / 16)$ & $22.58 \%(7 / 31)$ & $25.00 \%>22.58 \%, p=0.86(C Y)$ \\
\hline DEF: Suspicious Stress & $4.26 \%(2 / 47)$ & $0.00 \%(0 / 16)$ & $6.45 \%(2 / 31)$ & $0.00 \%<6.45 \%, p=0.78(C Y)$ \\
\hline DEF: Normal Stress & $70.21 \%(33 / 47)$ & $75.00 \%(12 / 16)$ & $67.74 \%(21 / 31)$ & $75.00 \%>67.74 \%, p=0.86(\mathrm{CY})$ \\
\hline DEF: High stress & $25.53 \%(12 / 47)$ & $25.00 \%(4 / 16)$ & $25.81 \%(8 / 31)$ & $25.00 \%<25.81 \%, p=0.77(\mathrm{CY})$ \\
\hline Total Stress: Suspicious Stress & $2.13 \%(1 / 47)$ & $0.00 \%(0 / 16)$ & $3.23 \%(1 / 31)$ & $0.00 \%<3.23 \%, p=0.73(\mathrm{CY})$ \\
\hline Total Stress: Normal Stress & $72.34 \%(34 / 47)$ & $75.00 \%(12 / 16)$ & $70.97 \%(22 / 31)$ & $75.00 \%>70.97 \%, p=0.96(\mathrm{CY})$ \\
\hline Total Stress: High Stress & $25.53 \%(12 / 47)$ & $25.00 \%(4 / 16)$ & $25.81 \%(8 / 31)$ & $25.00 \%<25.81 \%, p=0.77(\mathrm{CY})$ \\
\hline
\end{tabular}

${ }^{*}=$ significant test; $\mathrm{CY}=\mathrm{x}^{2}$ test with Yates correction; $\mathrm{StD}=$ Standard deviation, $T=\mathrm{t}$-Student test, $P D=$ Parental Distress, $P$-CDI $=$ Parental $-C$ hildren Distress Interaction, $D C=$ Difficulty Children, $D E F=$ Defensive Answer; Total stress $=(P D+P-C D I+D C)$;

Table 3 shows the characteristics of parents and their children, considering parents with elevated or suspicious stress only.

In particular, only 13 in 47 parental questionnaires revealed increased stress. One of these questionnaires fell in the defensive response category with an exceptionally low stress score (PSI-SF score $=40)$. In this case, the individual was a married female of 37 with no work income and a high school diploma, and a male child of 2 years with a severe disease.

Table 3 shows a significant presence of female (69.23\%, $p=0.0027)$, married subjects $(84.62 \%, p<$ $0.0001)$, patents unemployed $(69.23 \%, p=0.0027)$ and individuals with a middle school education level (61.54\%, $p=0.0084$ ). Among the children's characteristics, the most frequent feature was ill children with one sibling $(53.85 \%, p=0.0375)$.

Table 4 reports two groups: a group of parents with normal stress (PNS) (32.29\% males and 64.71\% females and an age range of 21-51 years, a mean of 38.53 and a standard deviation of 8.82 years), and a second group of parents with suspicious or elevated stress (PES) (30.67\% males and $69.23 \%$ females, an age range of $28-58$ years, a mean of 39.77 and a standard deviation 5.25 of years).

A significant presence of children with one sibling in the PNS group was observed compared to the PES group with $52.94 \%>7.69 \%(p=0.013)$. In addition, a significant presence of children with low Clinical Severity was revealed in the PNS group, while a remarkable number of children with a severe disease was observed in the PES group compared to the PNS group with $30.77 \%>2.94 \%$, $(p=0.0252)$.
Finally, Table 5 shows both univariate and a multivariate linear regression analysis between Total stress evaluated with the standardized questionnaire PSI-SF, and the independence variables associated to parents such as Age, Gender parents, Civil Status, Job, Education level, and between Total stress and the independent variables associated to children such as Children's Age, Age at diagnosis, Number of siblings, Birth order and Clinical Severity.

The univariate analysis pointed out a significant positive association between Total stress and children's Clinical Severity, indicating that parent stress was directly proportional to child Clinical Severity. In the multivariate analysis, i.e. considering simultaneously for children: age, gender, age at diagnosis, clinical severity, number of siblings and birth order, it resulted that the Number of siblings was a negative predictor of Total stress variable, while Birth order was a significant positive predictor of Total stress variable; in other words, an increased number of siblings represents a predictor of a decrease of parenting stress level, vice versa for Birth order.

Finally we observed in Total stress variable a significant presence of parents with normal stress $(72.34 \%=34 / 47)$ in contrast to parents with high stress $(25.53 \%=12 / 47)$ including subject with suspicious stress $(2.13 \%=1 / 47)$, i.e. it resulted: $72.34 \%(34 / 47)>27.66 \%$ (13/47), $p<0.0001$.

\section{Discussion}

In this study we analyzed parenting stress of children affected by Cystic Fibrosis through a biopsychosocial approach. The latter, which is supported both by the World Health Organization (WHO) and many data [13, 
Table 3 Characteristics of both parents and children, considering parents with elevated or suspicious stress only Parent's characteristics with Percentage/ mean \pm StD Statistical analysis Clinically elevated or

suspicious stress (nr. $=13$ )

\begin{tabular}{|c|c|c|}
\hline Age & 39.77 у.о. \pm 5.25 у.о. & \\
\hline \multicolumn{3}{|l|}{ Gender } \\
\hline Male & $30.77 \%(4 / 13)$ & $\begin{array}{l}30.77 \%<69.23 \% \\
p=0.0027^{\mathrm{a}} \text { (B) }\end{array}$ \\
\hline Female & $69.23 \%(9 / 13)$ & \\
\hline \multicolumn{3}{|l|}{ Civil status } \\
\hline Not married & $15.38 \%(2 / 13)$ & $\begin{array}{l}15.38 \%<84.62 \% \\
p<0.0001^{\mathrm{a}}(\mathrm{B})\end{array}$ \\
\hline Married & $84.62 \%(11 / 13)$ & \\
\hline \multicolumn{3}{|l|}{ Job } \\
\hline Worker with income & $30.77 \%(4 / 13)$ & $\begin{array}{l}30.77 \%<69.23 \% \\
p=0.0027^{\mathrm{a}}(\mathrm{B})\end{array}$ \\
\hline Unemployed & $69.23 \%(9 / 13)$ & \\
\hline Education level & & $p=0.0026^{\mathrm{a}}(\mathrm{C})$ \\
\hline Elementary school & $0.0 \%(0 / 13)$ & \\
\hline Middle school & $61.54 \%(8 / 13)$ & $\begin{array}{l}\text { Middle school }{ }^{b}, \\
p=0.0084(Z)\end{array}$ \\
\hline High school & $15.38 \%(2 / 13)$ & \\
\hline Higher Education & $23.08 \%(3 / 13)$ & \\
\hline Children's characteristics & Percentage/ mean \pm StD & Statistical analysis \\
\hline Age & 9.38 y.o. \pm 4.01 у.о. & \\
\hline \multicolumn{3}{|l|}{ Gender } \\
\hline Male & $53.85 \%(7 / 13)$ & $\begin{array}{l}53.85 \%>46.15 \% \\
p=0.58 \text { (B) }\end{array}$ \\
\hline Female & $46.15 \%(6 / 13)$ & \\
\hline Age at diagnosis & 1.77 y.o \pm 1.48 y.o. & \\
\hline Number of siblings & & $p=0.0173^{\mathrm{a}}(\mathrm{C})$ \\
\hline Zero & $7.69 \%(1 / 13)$ & \\
\hline One & $53.85 \%(7 / 13)$ & One $^{b}, p=0.0375(Z)$ \\
\hline Two & $30.77 \%(4 / 13)$ & \\
\hline Three & $7.69 \%(1 / 13)$ & \\
\hline Birth order & & $p=0.109(C)$ \\
\hline First & $7.69 \%(1 / 13)$ & \\
\hline Second & $46.15 \%(6 / 13)$ & \\
\hline Third & $30.77 \%(4 / 13)$ & \\
\hline Fourth & $15.38 \%(2 / 13)$ & \\
\hline Clinical Severity & & $p=0.236(C)$ \\
\hline Low & $15.38 \%(2 / 13)$ & \\
\hline Moderate & $46.15 \%(6 / 13)$ & \\
\hline Severe & $30.77 \%(4 / 13)$ & \\
\hline No defined & $7.69 \%(1 / 13)$ & \\
\hline
\end{tabular}

+ stress expressed i percentile and evaluated according to the PSI-SF scale, ${ }^{a}=$ significant test,${ }^{b}=$ most frequent, ${ }^{c}=$ less frequent, $C=$ Multiple comparison $x^{2}$ test, $Z=Z$-test, $B=$ exact Binomial test, $S t D=$ Standard deviation, $P D=$ Parental Distress, $P-C D I=$ Parental - Children Distress Interaction, $D C=$ Difficulty Children; Total stress $=(P D+P-C D I+D C)$
14], indicates that healthcare professionals should provide adequate healthcare assistance to children with the disease as well as a psychological support to their parents in order to improve their overall quality of life. The care should include biomedical and psycho-social interventions to achieve a positive impact on patient's life.

Contrary to our expectations [15-18], the study revealed a significant presence of parents with normal stress level. We hypothesize that this result may be attributed to the low Clinical Severity of the children enrolled in this study (Tables 4 and 5). In addition, we found a positive correlation between Clinical severity and Total stress, i.e. it was observed an increasing of abnormal stress in parents connected to an increasing of clinical severity in children. This result was not detected in a previous review [4]. We also investigated on additional parameters to identify possible correlations with parenting stress such as education levels, civil status, number of siblings, clinical status, etc. A significant correlation was found between stress levels and number of siblings in a multivariate analysis, i.e. the presence of more children in the same family is associated with high parental stress levels. This may be due to the higher commitment of parents in having to manage more children, when repeated hospitalizations cause more stress [19]. In terms of Birth order, the study has shown that parents of children with chronic illness bear higher stress level compared to other parents, and in particular, a high Birth order in a family with a child with the disease, implies parents with high or suspicious stress, whereas a low Birth order in a family predicts parents with normal stress levels. It has been recently shown that the mother first born interaction differs from the mother second born interaction in healthy children [20].

Our results may suggest that the increased distress observed in parents of children with chronic disease is probably affected by the great expectations that parents have on their first child.

In the event of a sick, the parents need a mental readjustment between their expectations of an ideal child and the real child status. The Clinical Severity analysis revealed a correlation between parental stress levels and degree of clinical severity, that is parental stress is higher in parents with a child with a severe disease and less in parents with a child with low Clinical Severity.

With regard to the total scores among stress subscales (Parenting Distress - PD, Parent-Child Dysfunctional Interaction P-CDI, Difficult Child (DC), the lowest score of parents with normal stress value was reported in the P-CDI sub-scale. P-CDI sub-scale measures parents' expectations and interactions with their child. High scores in P-CDI may indicate a parent's feelings of disappointment either caused by the child or by a lack of proper bonding with their child [21]. The set of 
Table 4 Characterization and Comparison between normal stress and suspicious or elevated stress group

\begin{tabular}{|c|c|c|c|}
\hline Parent's characteristics & $\begin{array}{l}\text { Group with } \\
\text { normal stress }\end{array}$ & $\begin{array}{l}\text { Group with suspicious } \\
\text { or elevated stress }\end{array}$ & $\begin{array}{l}\text { Normal vs. suspicious } \\
\text { or elevated stress Group }\end{array}$ \\
\hline Age (mean \pm StD y.o.) & $38.53 \pm 8.82$ & $39.77 \pm 5.25$ & $38.53<39.77, p=0.64(\mathrm{~T})$ \\
\hline \multicolumn{4}{|l|}{ Gender } \\
\hline Male & $35.29 \%(12 / 34)$ & $30.77 \%(4 / 13)$ & $35.29 \%>30.77 \%, p=0.96(C Y)$ \\
\hline Female & $64.71 \%(22 / 34)$ & $69.23 \%(9 / 13)$ & $64.71 \%<69.23 \%, p=0.96(C Y)$ \\
\hline \multicolumn{4}{|l|}{ Civil status } \\
\hline Not married & $8.82 \%(3 / 34)$ & $15.38 \%(2 / 13)$ & $8.82 \%<15.38 \%, p=0.90(\mathrm{CY})$ \\
\hline Married & $91.18 \%(31 / 34)$ & $84.62 \%(11 / 13)$ & $91.18 \%<84.62 \%, p=0.90(C Y)$ \\
\hline \multicolumn{4}{|l|}{ Job } \\
\hline Worker with income & $50.00 \%(17 / 34)$ & $30.77 \%(4 / 13)$ & $50 \%>30.77 \%, p=0.90(C Y)$ \\
\hline Unemployed & $50.00 \%(17 / 34)$ & $69.23 \%(9 / 13)$ & $50 \%<69.23 \%, p=0.90(C Y)$ \\
\hline \multicolumn{4}{|l|}{ Education level } \\
\hline Elementary school & $2.94 \%(1 / 34)$ & $0.00 \%(0 / 13)$ & $2.94 \%>0.00 \%, p=0.61(C Y)$ \\
\hline Middle school & $50.00 \%(17 / 34)$ & $61.54 \%(8 / 13)$ & $50.00 \%<61.54 \%, p=0.70(\mathrm{CY})$ \\
\hline High school & $32.35 \%(11 / 34)$ & $15.38 \%(2 / 13)$ & $32.35 \%>15.38 \%, p=0.42(C Y)$ \\
\hline Higher Education & $14.71 \%(5 / 34)$ & $23.08 \%(3 / 13)$ & $14.71 \%<23.08 \%, p=0.80(\mathrm{CY})$ \\
\hline Children's characteristics & $\begin{array}{l}\text { Group with } \\
\text { normal stress }\end{array}$ & $\begin{array}{l}\text { Group with suspicious } \\
\text { or elevated stress }\end{array}$ & $\begin{array}{l}\text { Normal vs. suspicious } \\
\text { or elevated stress Group }\end{array}$ \\
\hline Age (mean \pm StD y.o.) & $7.82 \pm 5.04$ & $9.38 \pm 4.01$ & $7.82<9.38, p=0.32(\mathrm{~T})$ \\
\hline \multicolumn{4}{|l|}{ Gender } \\
\hline Male & $55.88 \%(19 / 34)$ & $53.85 \%(7 / 13)$ & $55.88 \%>53.85 \%, p=0.84(C Y)$ \\
\hline Female & $44.12 \%(15 / 34)$ & $46.15 \%(6 / 13)$ & $44.12 \%>46.15 \%, p=0.84(C Y)$ \\
\hline Age at diagnosis (mean \pm StD y.o.) & $1.59 \pm 1.35$ & $1.77 \pm 1.48$ & $1.59<1.77, p=0.69(\mathrm{~T})$ \\
\hline \multicolumn{4}{|l|}{ Number of siblings } \\
\hline None & $52.94 \%(18 / 34)$ & $7.69 \%(1 / 13)$ & $52.94 \%>7.69 \%, p=0.013^{a}(C Y)$ \\
\hline One & $41.18 \%(14 / 34)$ & $46.15 \%(6 / 13)$ & $41.18 \%<46.15 \%, p=0.96(C Y)$ \\
\hline Two & $5.88 \%(2 / 34)$ & $30.77 \%(4 / 13)$ & $5.88 \%<30.77 \%, p=0.072(\mathrm{CY})$ \\
\hline Three & $0.00 \%(0 / 34)$ & $15.38 \%(2 / 13)$ & $0.00 \%<15.38 \%, p=0.13(C Y)$ \\
\hline \multicolumn{4}{|l|}{ Birth order } \\
\hline First & $61.76 \%(21 / 34)$ & $53.85 \%(7 / 13)$ & $61.76 \%>53.85 \%, p=0.87(C Y)$ \\
\hline Second & $38.24 \%(13 / 34)$ & $30.77 \%(4 / 13)$ & $38.24 \%>30.77 \%, p=0.87(C Y)$ \\
\hline Third & $0.00 \%(0 / 34)$ & $7.69 \%(1 / 13)$ & $0.00 \%<7.69 \%, p=0.61(C Y)$ \\
\hline Fourth & $0.00 \%(0 / 34)$ & $7.69 \%(1 / 13)$ & $0.00 \%<7.69 \%, p=0.61(C Y)$ \\
\hline \multicolumn{4}{|l|}{ Clinical Severity } \\
\hline Low & $67.65 \%(23 / 34)$ & $15.38 \%(2 / 13)$ & $67.65 \%>15.38 \%, p=0.0039^{a}(C Y)$ \\
\hline Moderate & $29.41 \%(10 / 34)$ & $46.15 \%(6 / 13)$ & $29.41 \%<46.15 \%, p=0.46(C Y)$ \\
\hline Severe & $2.94 \%(1 / 34)$ & $30.77 \%(4 / 13)$ & $2.94 \%<30.77 \%, p=0.0252^{a}(C Y)$ \\
\hline
\end{tabular}

${ }^{a}=$ significant test; $C Y=x^{2}$ test with Yates correction, $S t D=$ Standard deviation, $T=\mathrm{t}$-Student test;

questions made it possible to investigate the parentchild relationship and to point out whether the parent perceived the relationship with their child to be different from the one they expected in a no sick child, (i.e. "My child is not able to do as much as I expected", "When I do things for my child, I feel that my efforts are not much appreciated", "My son does not seem to learn as fast as most children do!"). It is clear that the illness event in these parents also negatively influences parentchild dynamics [22].

Similarly, none of the sub-categories has shown any remarkable difference between fathers and mothers in terms of high stress (including stress to be assessed and high stress) $25.0<29.03 \%$. In this case, a higher level of 
Table 5 Univariate and multivariate linear regression analysis between Total stress and Age parents, Gender parents, Civil status, Job, Education level, Age children, Gender children, Age at diagnosis, Number of siblings, Birth order, Clinical Severity

\begin{tabular}{lll}
\hline Linear correlation analysis & $\begin{array}{l}\text { Univariate analysis } \\
R(p \text {-value })\end{array}$ & $\begin{array}{l}\text { Multivariate analysis } \\
\text { Rpartial; } p \text {-value }\end{array}$ \\
\hline & & Multiple linear correlation coefficient $=0.22$ \\
Total Stress / Age parents & $0.09(0.56)$ & Rpartial $=0.12 ; p$-value $=0.43$ \\
Total Stress / Gender parents & $0.02(0.87)$ & Rpartial $=0.09 ; p$-value $=0.59$ \\
Total Stress / Civil status & $-0.12(0.42)$ & Rpartial $=-0.15 ; p$-value $=0.34$ \\
Total Stress / Job & $-0.08(0.58)$ & Rpartial $=-0.13 ; p$-value $=0.39$ \\
Total Stress / Education level & $-0.03(0.83)$ & Rpartial $=-0.07 ; p$-value $=0.67$ \\
& & Multiple linear correlation coefficient $=0.51$ \\
Total Stress / Age children & $0.25(0.08)$ & Rpartial $=-0.03 ; p$-value $=0.83$ \\
Total Stress / Gender children & $-0.1(0.51)$ & Rpartial $=-0.15 ; p$-value $=0.36$ \\
Total Stress / Age at diagnosis & $0.1(0.52)$ & Rpartial $=0.05 ; p$-value $=0.76$ \\
Total Stress / Number of siblings & $0.28(0.05)$ & Rpartial $=0.34 ; p$-value $=0.0282^{\text {a }}$ \\
Total Stress / Birth order & $-0.15(0.31)$ & Rpartial $=-0.37 ; p$-value $=0.0177^{\text {a }}$ \\
Total Stress / Clinical Severity & $0.30(0.0424) *$ & Rpartial $=0.14 ; p$-value $=0.38$ \\
\hline
\end{tabular}

${ }^{\mathrm{a}}=$ significant test; $R=$ Pearson's linear correlation coefficient; $R \_$partial = the partial correlation coefficient is the

coefficient of correlation of the variable with the dependent variable, adjustment due to the impact of the other variables on the mode; $P D=$ Parental Distress, $P-C D I=$ Parental - Children Distress Interaction, $D C=$ Difficulty Children, Total stress $=(P D+P-C D I+D C)$;

stress in mothers would have been more likely expected as they are normally more involved in the history of the disease. As they are nearly always hospitalized together with the child, these mothers could be overloaded with more stress $[18,23]$.

However, despite the small number of parents with clinically elevated or suspicious stress $(27.66 \%)$, their features were nonetheless analyzed.

Considering parents with high or suspicious stress levels only (Table 3), a higher presence of mothers was observed as opposed to fathers $(69.23 \%>30.77)$, the mean age was of about 40 years, married individuals were the majority $(84.62 \%)$, and there was a substantial presence of individuals without regular paid job (69.23\%) and a middle school education level (61.54\%). Finally, among the examined parents, high stress was detected in parents having a second child (53.85\%) with Cystic Fibrosis, i.e. an ill child with one sibling.

\section{Conclusion}

This study has shown that, despite the fact that a child's chronic disease inevitably puts a heavy stress on a family, making them vulnerable and emotionally exposed, an effective multidisciplinary care plan, that takes into account the emotional and sympathetic aspect of caregivers, would help parents development of internal resources to allow them to cope with stress. Such comprehensive model of management with a regularly provided psychological support appears to be a key factor for coping and for achieving a strong therapeutic alliance between healthcare professionals and patients, in other words a strong psychological support fits particularly well in the biopsychosocial model of comprehensive are in this progressively worsening disease.

\section{Limitations}

The current study has some limitations. As the size of the sample drawn for the current analysis was relatively small compared with other studies examining the psychometric properties of the PSI-SF, the aim of the study may be limited in its. For this reason, the data presented should be interpreted as preliminary results, although they open the way to encourage future research on the psychometric properties of the PSI-SF with larger samples and similar demographic compositions within a multi-center study. However, despite such limitations, the study has demonstrated that the clinical management of CF children should include a psychological support to parents since parenting stress does play a fundamental role in the effectiveness and efficacy of treatments as well as in patients' quality of life.

\section{Abbreviations}

CF: Cystic fibrosis; PSI-SF: Parenting stress index - short form questionnaire; CFTR: ; WHO: World health organization; SA: Strongly agree; NS: Not sure; D: Disagree; SD: Strongly disagree; PD: Parenting distress; P-CDI: Parent-child dysfunctional interaction; DC: Difficult child; DEF: Defensive response; PNS: Group of parents with normal stress; PES: Group of parents with suspicious or elevated stress; R: Pearson's linear correlation coefficient; p: P-value.

Acknowledgements

The authors GIC and NS contributed equally to this work. 


\section{Authors' contributions}

GIC conceived and designed the study, interpreted the psychological data and contributed to writing the manuscript; MTC collected data; GG, SS, ST and MRE defined the database and contributed to writing the manuscript: TR: contributed to the designed and reviewed the manuscript; NS: performed statistical analysis and interpretation of data, writing the manuscript and reviewed the final draft, ST and AG: performed the interviews; AS and VR: defined the enrolled patients and revised the manuscript. The author (s) read and approved the final manuscript.

\section{Funding}

This study was funded by Cystic Fibrosis Foundation and therapeutics. Award number: GUARIN10A0. The Cystic Fibrosis Foundation and therapeutics had no role in the study design; in the collection, analysis and interpretation of data; in the writing of report, and in the decision to submit the paper for publication.

\section{Availability of data and materials}

The datasets during and/or analyzed during the current study available from the corresponding author on reasonable request.

\section{Ethics approval and consent to participate}

Informed consent was obtained from all parents of children included in the study. For all participants anonymity was guaranteed. No economic incentives were offered or guaranteed for their participation in the study.

The Local Ethical Committee approved the study. (Protocol number 2018 : 254/2018).

\section{Consent for publication}

not applicable.

\section{Competing interests}

The authors reported no conflicts of interest. The authors alone are responsible for the content and writing of this article.

\section{Author details}

${ }^{1}$ Department of Translational Medical Sciences, University Federico II of Naples, Naples, Italy. ${ }^{2}$ Department of Molecular Medicine and Medical Biotechnology, University Federico II of Naples, Naples, Italy. ${ }^{3}$ Department of Public Health, University Federico II of Naples, Naples, Italy. ${ }^{4}$ Department of Biomedicine and Prevention, University of Rome Tor Vergata, Rome, Italy. ${ }^{5}$ Istituto Nazionale Tumori Fondazione "G. Pascale", Naples, Italy.

\section{Received: 13 January 2020 Accepted: 25 February 2020}

\section{Published online: 18 March 2020}

\section{References}

1. Smyth $A R$, et al. European cystic fibrosis society standards of care: best practice guidelines. J Cyst Fibros. 2014;13:S23-42. https://doi.org/10.1016/j. jcf.2014.03.010

2. De Boeck K. Cystic fibrosis in the year 2020: a disease with a new face. Acta Paediatr. 2020;00:1-7. https://doi.org/10.1111/apa.15155.

3. Jamieson N, Fitzgerald D, Singh-Grewal D, Hanson CS, Craig JC, Tong A. Children's experiences of cystic fibrosis: a systematic review of qualitative studies. Pediatrics. 2014;133(6):e1683-97. https://doi.org/10. 1542/peds.2014-0009.

4. Cousino MK, Hazen RA. Parenting stress among caregivers of children with chronic illness: a systematic review. J Pediatr Psychol. 2013;38(8):809-28. https://doi.org/10.1093/jpepsy/jst049.

5. Simeone S, Pucciarelli G, Perrone M, Rea T, Gargiulo G, Dell'Angelo G, Guillari A, Comentale G, Palma G, Vosa C. Comparative analysis: implementation of a pre-operative educational intervention to decrease anxiety among parents of children with congenital heart disease. J Pediatr Nurs. 2017;35:144-8.

6. Simeone S, Pucciarelli G, Perrone M, Dell'Angelo G, Teresa R, Guillari A, Gargiulo G, Comentale G, Palma G. The lived experiences of the parents of children admitted to a paediatric cardiac intensive care unit. Heart Lung. 2018:47(6):631-7.

7. Simeone S, Platone $N$, Perrone M, Marras V, Pucciarelli G, Benedetti M, Dell'Angelo G, Rea T, Guillari A, Da Valle P, Gargiulo G, Botti S, Artioli G, Comentale G, Ferrigno S, Palma G, Baratta S. The lived experience of parents whose children discharged to home after cardiac surgery for congenital heart disease. Acta bio-medica: Atenei Parmensis. 2018;89(Suppl 4):71.

8. Abidin RR. Parenting stress index. 3rd ed. Odessa: Psychological Assessment Resources; 1995

9. Zubrzycka R. Coping with stress by mothers of children and adolescents with cystic fibrosis. Adv Respir Med. 2018;86(2):86-91. https://doi.org/10. 5603/ARM.2018.0011.

10. Ullrich G, Bobis I, Bewig B. Parenting stress in mothers with cystic fibrosis. Disabil Rehabil. 2016;38(2):174-9. https://doi.org/10.3109/09638288.2015. 1031290 Epub 2015 Apr 10.

11. Abidin RR, Abidin RR. Parenting Stress Index (PSI) (p. 100). Charlottesville: Pediatric Psychology Press; 1990.

12. Guarino A, Di Blasio P, D'Alessio M, Camisasca E, Serantoni G. PSI: parenting stress index - short form: Italian version. Giunti OS; 2008. https:/www.giuntios. it/media/FlipBook/static/GiuntiOS_catalogo2012/files/assets/seo/page83.html.

13. Kusnanto H, Agustian D, Hilmanto D. Biopsychosocial model of illnesses in primary care: a hermeneutic literature review. J Family Med Prim Care. 2018; 7(3):497-500. https://doi.org/10.4103/jfmpc.jfmpc_145_17.

14. Wood BL, Miller BD, Lehman HK. Review of family relational stress and pediatric asthma: the value of biopsychosocial systemic models. Fam Process. 2015;54(2):376-89. https://doi.org/10.1111/famp.12139.

15. Estrela C, Barker ET, Lantagne S, Gouin JP. Chronic parenting stress and mood reactivity: the role of sleep quality. Stress Health. 2018;34(2):296-305. https://doi.org/10.1002/smi.2790.

16. Geense WW, van Gaal BGI, Knoll JL, Cornelissen EAM, van Achterberg T. The support needs of parents having a child with a chronic kidney disease: a focus group study. Child Care Health Dev. 2017;43(6):831-8. https://doi.org/ 10.1111/cch.12476.

17. Gray WN, Graef DM, Schuman SS, Janicke DM, Hommel KA. Parenting stress in pediatric IBD: relations with child psychopathology, family functioning, and disease severity. J Dev Behav Pediatr. 2013;34(4):237-44. https://doi.org/ 10.1097/DBP.0b013e318290568a.

18. Cousino MK, Hazen RA. Parenting stress among caregivers of children with chronic illness: a systematic review. J Pediatr Psychol. 2013;38(8):809-28. https://doi.org/10.1093/jpepsy/jst049.

19. Doupnik SK, Hill D, Palakshappa D, Worsley D, Bae H, Shaik A, Qiu MK, Marsac M, Feudtner C. Parent coping support interventions during acute pediatric hospitalizations: a meta-analysis. Pediatrics. 2017;140(3):e20164171. https://doi.org/10.1542/peds.2016-4171.

20. Bornstein MH, Putnick DL, Suwalsky JTD. Mother-infant interactions with firstborns and secondborns: a within-family study of European Americans. Infant Behav Dev. 2019;55:100-11. https://doi.org/10.1016/j.infbeh.2019.03. 009 Epub 2019 Apr 16.

21. Pinquart M. Parenting stress in caregivers of children with chronic physical condition-a meta-analysis. Stress Health. 2018;34(2):197-207. https://doi.org/ 10.1002/smi.2780

22. Wirlach-Bartosik S, Schubert MT, Freilinger M, Schober E. Family dynamics and chronic illness: children with diabetes in the context of their families. Klin Padiatr. 2005;217(5):253-8.

23. Nieuwesteeg A, Hartman E, Emons W, van Bakel H, Aanstoot $H J$, van Mil E, Pouwer F. Paediatric parenting stress in fathers and mothers of young children with type 1 diabetes: a longitudinal study. Diabet Med. 2017;34(6): 821-7. https://doi.org/10.1111/dme.13300

\section{Publisher's Note}

Springer Nature remains neutral with regard to jurisdictional claims in published maps and institutional affiliations.

Ready to submit your research? Choose BMC and benefit from:

- fast, convenient online submission

- thorough peer review by experienced researchers in your field

- rapid publication on acceptance

- support for research data, including large and complex data types

- gold Open Access which fosters wider collaboration and increased citations

- maximum visibility for your research: over $100 \mathrm{M}$ website views per year

At $\mathrm{BMC}$, research is always in progress.

Learn more biomedcentral.com/submissions 